\title{
HISTÓRIA AO PÉ DA LETRA: UMA INTRODUÇÃO À OBRA DE JULES MICHELET
}

\author{
Maria Juliana Gambogi Teixeira*
}

\begin{abstract}
Resumo: Este artigo apresenta, em grandes linhas, a obra e a fortuna crítica do historiador francês oitocentista Jules Michelet. Nosso objetivo é demonstrar como a fronteira entre história e literatura constitui, ao mesmo tempo e paradoxalmente, a condição de possibilidade de seu renome e o principal desafio para sua atualização.
\end{abstract}

Palavras-chaves: Fronteira entre história e literatura; Jules Michelet; fortuna crítica.

História ao pé da letra: assim poderia ser definido o pacto de leitura que, desde o século XIX até os dias atuais, dominou a recepção de um dos mais célebres historiadores franceses oitocentistas - Jules Michelet (1798-1874). Mas, nesse caso, o significado dessa expressão é muito preciso: ao invés de uma historiografia pura, historiografia tout court, a imagem designaria uma história submetida, vencida, literalmente aos pés da literatura. De fato, apesar da intratável recusa de Michelet em aceitar o título de poeta da história, sua obra sempre inspirou comentários nos quais o elogio ao texto vai de par com a dúvida quanto à confiabilidade historiográfica. Assim, num primeiro instante deste comentário, poder-se-ia apresentar sua produção sob a ótica de uma história "aos pés da Letras", como uma maneira de repercutir um dos retratos de Michelet mais caros à sua crítica: o de um historiador subjugado pelas seduções da Literatura.

* Universidade Federal de Minas Gerais. 
Essa submissão, por seu turno, tem dupla face. De um lado, ela evoca um historiador dominado pelas seduções da literatura, incapaz, portanto, de reconhecer ou resistir aos limites que separam uma e outra disciplina. O outro lado dessa mesma moeda chega com uma avaliação geral da fortuna crítica de Michelet, também ela claramente marcada pelo campo literário. Ou seja, foram e ainda hoje são escritores e especialistas da literatura que, prioritariamente, cuidam de receber a obra micheletiana, dessa maneira atestando - de forma explícita ou não - serem as Letras o espaço próprio e adequado à leitura desse historiador.

Situação limítrofe que, desde a contemporaneidade de Michelet até a nossa contemporaneidade, embora eficaz na perpetuação da fama desse historiador, parece ser incapaz de atualizá-lo. O objetivo deste artigo é o de recuperar, em linhas gerais, os impasses dessa recepção, tentando entender em que medida os embaraços ligados à interpretação de Michelet atualizam os dilemas próprios à interface entre a literatura e a história.

Antes, porém, seria interessante oferecer um panorama do que constitui a obra micheletiana. Ora, apresentar completa e coerentemente sua produção representa por si só um desafio ao qual, a princípio, somente a biografia poderia responder. ${ }^{1}$ Atendonos, apenas, às grandes linhas, poderemos observar uma matriz principal, representada pelos dezessete volumes que compõem o título Histoire de France. ${ }^{2}$ Este foi o fio narrativo mais extenso

\footnotetext{
${ }^{1}$ Michelet inspirou alguns trabalhos de tipo biográfico. Para citar os títulos mais contemporâneos e relevantes, elencamos os trabalhos dos dois principais especialistas nos estudos micheletianos: Paul Viallaneix, com Michelet, les travaux et les jours - 1798-1874, e Paule Petitier, comJules Michelet: l'homme histoire.

${ }^{2}$ Os dezessete volumes da edição inicial foram, muito recentemente, republicados, sob os cuidados de Paul Vaillaneix e Paule Petitier junto à editora Éditions des Équateurs. Já as obras completas de Michelet, prometidas e parcialmente publicadas pela Flammarion, permanecerão incompletas, visto a decisão da editora de abandonar o projeto.
} 
perseguido por Michelet: começando pela Gália Romana - entre César e Vercingetorix -, termina com o fim do século XVIII, narrando a história da Revolução Francesa. Alguns de seus livros mais célebres, tais como Renaissance et Réforme e Histoire de la Révolution Française ouJeanne d'Arc, participam, originalmente, desse projeto, cuja ambição à totalidade parece flagrante. Se o recorte temporal já confirmaria tal traço, a inflexão adotada pelo historiador corrobora essa magnitude: "Assim, ou tudo ou nada" - assume o autor. $^{3}$ Ver a França como "alma e pessoa", como ele afirmou ter visto nessa obra, significava cuidar de seu corpo - "raças", "solo", "clima", "alimentação", "tantas circunstâncias físicas e fisiológicas" que vão se alterando ao longo dos séculos -; cuidar também de seu espírito - das "leis", dos "atos políticos", das idéias, dos costumes, "do grande movimento progressivo, interior, da alma nacional" -; sem esquecer, ainda, dos "pequenos detalhes eruditos, em que o melhor, às vezes, permanecia escondido...." ${ }^{4}$ Realizado tomo a tomo, o projeto da Histoire de France levou trinta e quatro anos para ser concluído. Mas quando, em 1867, publicou seus últimos volumes, recomeçou, imediatamente, o trabalho, querendo, então, propor uma Histoire du XIX ${ }^{\grave{m} e}$ siècle. Ausente do projeto inicial, essa história foi interrompida em seu terceiro tomo, com a morte, em 1874, do historiador. ${ }^{5}$

O título magno, no entanto, esteve longe de esgotar o frenesi produtivo de Michelet. Abrindo interstícios em meio ao projeto maior, surgem títulos paralelos e filóes à primeira vista estranhos à historiografia. Neste último caso, o destaque fica com a série de história natural: L'Oiseau (1856); L'Insecte (1857); La Mer (1861);

\footnotetext{
${ }^{3}$ MICHELET. Préface de 1869. Oeuvres complètes, t. IV, p. 23. Salvo menção contrária, todas as traduções neste artigo são de minha autoria.

${ }^{4}$ MICHELET. Préface de 1869. Oeuvres complètes, t. IV, p. 13.

${ }^{5}$ Os dois primeiros tomos foram publicados em vida, ao passo que o terceiro veio a público como obra póstuma. Sua mais recente edição se deve a Flammarion e corresponde ao volume XXI das Oeuvres complètes.
} 
e La Montagne (1868), livros nos quais mescla divulgação científica e elucubrações de ordem moral. Outro filão significativo se organiza em torno dos chamados "livros de combate" - para recorrer à terminologia proposta por Daniel Halévy ${ }^{6}$ - cuja temática aborda as grandes questões político-sociais de seu tempo. Dentre os vários títulos que podem ser arrolados nessa categoria, destaquem-se Du Prêtre, de la femme et de la famille (1845), tratando da questão religiosa; Le Peuple (1846), para a questão social; L'Amour (1858) e La Femme (1859), um duo sobre a questão feminina, e Nos Fils (1869), sobre a educação.

Se isso não é pouco, tampouco é tudo. Resta, pois, mencionar as obras que, sem pertencerem ao título Histoire de France, funcionam como seus suplementos historiográficos, tais como Histoire romaine (1831), Mémoires de Luther (1835), Les Femmes de la Révolution (1854), La Bible de l'bumanité (1864), não se esquecendo da mais famosa: La Sorcière, de 1862. Tampouco seria possível deixar de lado a produção de tônica marcadamente teórica, característica de seus anos de formação, mas cujos efeitos são sentidos e reconhecidos ao longo de toda a obra do historiador. Neste ínterim, lembro que Michelet foi o primeiro tradutor e principal divulgador das teorias filosóficas do napolitano setecentista Giambattista Vico, assim como manteve correspondência intensa e frutífera com Jacob Grimm, nome fundamental da filologia histórica alemã. De cada um desses contatos, resultam frutos distintos: de Vico, a tradução da Scienza Nuova (Principes de la philosophie de l'histoire), em 1827, e das Oeuvres choisies de Vico, em 1835; enquanto vem de Grimm a inspiração para Origines $d u$ droit français, de 1837. A enganosa pontualidade sugerida pelos três títulos se desfaz quanto mais se observa seu papel angular na produção subseqüente. E uma das maneiras de

\footnotetext{
${ }^{6}$ Importante historiador na primeira metade do século XX e leitor contumaz de Michelet, Halévy tem trabalhos importantes sobre o historiador. No caso da expressão citada, ela se encontra em: HALÉVY. Les trois vies de Jules Michelet.
} 
se comprovar essa influência encontra-se na leitura de sua marginália, último filão a ser, aqui, evocado: além das várias revisões que impôs a cada volume de suas Histoires, há o Diário, mantido ao longo de toda a sua vida, uma imponente Correspondência - já integralmente publicada -, além das notas dos cursos proferidos na École normale e no Collège de France.

Obra tão extensa quanto variada, ela parece guardar consigo o estranho sortilégio de se fazer maior à medida que fez habitar, lado a lado, traços contrastantes entre si: poética e historiográfica, erudita e panfletária, clássica e moderna. Assim, quando o leitor se aventura em quaisquer de seus títulos, vê-se, num primeiro momento, instado a abandonar qualquer definição exclusiva desse autor, a qual não admitisse, imediatamente, acolher o seu contrário. Bem verdade que, flertando com a filosofia, com a literatura, com a política e com as ciências naturais, Michelet não pretendeu nem admitia outro título senão o de historiador. Ante ao coro de seus contemporâneos ressaltando seu gênio poético, Michelet sempre retorquia, denunciando a dubiedade de um "elogio" que, na realidade, serviria "como forma de me destruir e me negar qualquer autoridade". ${ }^{7}$ Manifestamente, sabia muito bem que, pelo menos desde Aristóteles, o maior antagonista da história se chamava literatura.

\section{Ao pé da Letras}

Ironia do destino: foi a literatura quem salvou esse historiador do olvido. Ou seja, foram os comentários (mais ou menos azedos) de um Taine, de um Saint-Beuve ou de um Huysmans, ao lado da admiração de Hugo, Flaubert, Zola, Proust (entre tantos outros), que garantiram a essa obra uma sobrevida não partilhada pela de seus pares. ${ }^{8}$ Com efeito, este é o ponto

\footnotetext{
${ }^{7}$ MICHELET. Préface de 1869. Oeuvres complètes, t. IV, p 20.
} 
para o qual convergem as duas principais matrizes de recepção micheletiana: a propensão a "transferir" as obras desse historiador, das prateleiras da história, para as da literatura.

Não por acaso, a contextualização de Michelet vem a reboque de uma periodização propriamente literária, cunhada em torno do Romantismo. Daí um conjunto de postulados mais ou menos negativos, associando esse autor a uma série de derivações semânticas do substantivo romantismo: historiador romântico, gênio intuitivo, imaginação exacerbada, entre outros. ${ }^{9}$

\footnotetext{
${ }^{8}$ Sobre a recepção "literária" de Michelet em sua época, as fontes mais completas são, sem dúvida, as biografias. Outra fonte interessante está em: CARRÉ. Michelet et son temps.

${ }^{9}$ Um dos melhores exemplos dessa recepção historiográfica se encontra no livro O tempo da história, de Philippe Ariès. Apesar de extenso, merece uma citação integral: "O historiador romântico, Augustin Thierry ou Michelet, propunhase a evocar o passado, fazê-lo reviver com todos os seus aspectos pitorescos e saborosos, com a sua cor própria. No relato autêntico dos acontecimentos passados, os historiadores procuravam o mesmo desenraizamento que poetas e romancistas pediam à ficção, e à ficção histórica. Ora, essa preocupação de desenraizamento, que dali em diante orientava o historiador para o quadro vivo, era justamente um sentido rudimentar da diferença entre os tempos. Rudimentar, porque se satisfazia com uma evocação simplesmente pitoresca e permanecia na superfície das coisas: era mais o gosto das curiosidades do que o das variações em profundidade da estrutura mental ou social. Porém, esse espanto diante do passado permanecia sendo uma importante aquisição da história. Descobria-se com entusiasmo o que era o outro. É por isso que, apesar de suas lacunas e seus erros, Michelet conserva ainda hoje (e hoje mais do que ontem) um interesse apaixonante. Ele era sensível demais às singularidades da história para não ter apreendido, por intuição, os contrastes, as diferenças que o historiador contemporâneo reencontra com uma base científica mais segura, mas sem contradizer quanto ao fundo as intuições divinatórias, embora incertas, do romântico genial. Faltava, porém, aos autores dessa primeira metade do século XIX um método crítico para estabelecer uma documentação segura. (...) Por isso, exceto algumas intuições de visionário de Michelet, sua obra permanece hoje letra morta." (ARIÉS. O tempo da história, p. 212).
} 
Apesar de sua difusão, essa chave de leitura é problemática. ${ }^{10}$ O primeiro problema liga-se ao fato de o termo ser utilizado para elencar uma geração de historiadores (da qual fizeram parte, entre outros, Cousin, Guizot, Barante, Ballanche, Mignet, Thiers, Thierry, Michelet, Quinet) que, embora reunidos na ambição comum de dotar de cientificidade a disciplina histórica recém-nata, o fizeram através da confecção de teorias e práticas muito divergentes entre si. A isso se acresce a dificuldade de definição do Romantismo, aparentemente mais compacto no caso da Alemanha e da Inglaterra, mas, na França, teoricamente frouxo, e requisitado para nomear, mesmo dentro da literatura, projetos muito díspares, nenhum (até onde pudemos pesquisar), partindo dessa geração de historiadores.

Talvez a inocuidade da etiqueta diminua quando restrita a apartar um conjunto heterogêneo de idéias sobre a história, típico da geração a qual pertenceu Michelet, de uma concepção posterior, mais coesa e ainda atuante, assentada em fundamentos de cientificidade tomados do positivismo. Ao fim, caso se compreenda que o paradigma positivo, se fundador da prática moderna da história, se respalda na adoção de um método científico em cujo cerne estaria um veto nem tanto aos pendores artísticos, mas a certos ardores filosóficos, dispostos a submeter o termo História a uma interrogação de tipo mais sistêmico do que metodológico, então, decididamente, Michelet e os de sua geração encontram-se fora dela. Quanto a supor que, na ausência de tais parâmetros, qualquer postura historiográfica esteja definitivamente desautorizada enquanto tal ou possa ser tratada como pré-história, isso já seria, no mínimo, um anacronismo.

\footnotetext{
${ }^{10}$ Para uma visada crítica do recorte feito em torno da historiografia romântica, ver, em particular: GAUCHET. Philosophie des sciences historiques. e LEFORT. La cité des vivants et des morts.
} 
A segunda matriz principal de recepção da obra micheletiana é a literária. Inaugurada pelos contemporâneos do historiador, embora não seja exatamente prolífica, soube ser constante, mobilizando a atenção de gerações de estudiosos e escritores. ${ }^{11}$ Mas se a literatura é protagonista nos estudos micheletianos, também notável é o papel de Roland Barthes dentro desse campo. Certo que Barthes não esteve sozinho na empreitada de atualizar a leitura micheletiana, mas foi um dos que mais e melhor se dedicou à tarefa. Para isso, o semiólogo privilegiou não exatamente a competência narrativa do historiador (ademais, duvidosa inclusive para os seus mais compassivos leitores), mas os muitos instantes em que seus textos parecem extraviar-se do domínio do enunciado, do pragmatismo narrativo ou da referencialidade.

Em particular, sua noção de escritura oferece uma forma de aproximar o texto micheletiano da cena moderna, ao mesmo tempo em que evita o tema das fronteiras entre literatura e história, apostando em algo da ordem de um para além dos limites disciplinares. Lembremos que tal noção visa redefinir o campo do literário, não mais entendido como "um corpo ou seqüência de obras", mas como "tecido de significantes", cuja característica é a de "combater e desviar o poder totalitário da língua a partir da própria língua: a escritura." 12

\footnotetext{
${ }^{11}$ Sem qualquer pretensão à exaustividade, essa matriz pode ser dividida em dois campos. De um lado, o campo dos estudiosos da literatura, especialistas ou não em história literária, cujas obras, desde Lanson, não se esquecem de reservar um espaço mais ou menos importante para esse historiador. Dessa matriz, podem ser citados, apenas a título de exemplo, os trabalhos hoje clássicos de Paul Bénichou sobre o século XIX. Além dele e ao lado daqueles que, efetivamente, se especializaram na obra micheletiana (e cujo grande nome, em atividade, é o de Paule Petitier), vale mencionar ainda a atração que o historiador exerceu sobre os escritores ao longo dos séculos XX e XXI. Nesse caso, podemos citar, entre vários outros, Marcel Proust, Marguerite Duras e, muito recentemente, Pierre Michon.
}

${ }^{12}$ BARTHES. Aula, p. 17 e seguintes. 
Sob um tal prisma, a obra de Michelet abre-se para leituras que, menos interessadas no contexto do historiador do que em seus textos, garante a esses escritos uma abordagem autônoma, assegurada pela economia interna e própria do gesto criativo:

O que torna Michelet escritor (praticante da escritura, operador de texto) não é o seu estilo (que nem sempre é muito bom, às vezes sendo precisamente apregoação de estilo), é o que hoje chamamos de excesso de significante. Esse excesso se lê nas margens da representação. ${ }^{13}$

Essas margens responderiam pelo corte característico à leitura de tipo discriminatório defendida por Barthes, a partir da qual se poderia dissociar o texto de Michelet de seu patbos ideológico, patbos este responsável pela "inatualidade" do historiador.

Menos do que discutir a tese de Barthes, interessa perseguir algumas causas levantadas pelo semiólogo para a resistência do texto de Michelet em se fazer atual. Independentemente do significado que se queira atribuir à "atualidade", merece destaque o fato de esse patbos ideológico mencionado por Barthes indicar, muito simplesmente, a visão de mundo do historiador. Essa visão de mundo diz respeito a tudo o que o demarca como homem de sua época: suas crenças, suas dúvidas, seus gostos, suas expectativas, sua linguagem. $\mathrm{O}$ aspecto social inerente a essa questão sublinha, nesse caso, o sujeito histórico, em detrimento do sujeito privado. Ou seja, é a historicidade de Michelet a responsável por sua perdição - preso à linguagem do século XIX, sua história o condena. Curiosamente, tratase do mesmo argumento arrolado pelos historiadores atuais quando comentam a ilegibilidade de sua produção - enquadrado pelo Romantismo, sua historiografia é inatual.

Consequentemente, essa ideologia micheletiana - no que tem de avessa à Modernidade e, sobretudo, à escritura - só fora superficialmente abordada por Barthes, visto seu objetivo ter sido,

${ }^{13}$ BARTHES. O rumor da língua, p. 213. 
justamente, o de garantir atualidade aos textos do historiador. Por outro lado, caberia reconhecer que a presença dessa ideologia (que curiosamente Barthes nomeia como a "pele" de Michelet) foi objeto de enorme investimento do historiador, que não só costumava defendê-la, como o fazia a fim de se defender das ideias da época. Assim, ao menos parte dessa "apregoação de estilo", desse patbos micheletiano é não apenas auto-reflexivo quanto se converte em fundamento para os seus constantes desvios da norma, das convenções e dos modelos narrativos e ou epistemológicos praticados em seu tempo, ou seja, do excesso de significante, tão positivo aos olhos de Barthes. Consequentemente, parece possível pensar que se a leitura discriminatória, tal como professada por Barthes, fracassa (conforme sugere o próprio autor) como método de atualização de Michelet, isso em parte se deve à sua resistência a acatar a posição de Michelet segundo a qual, não sendo poeta da história, fora, acima de tudo, um historiador ao pé da letra.

\section{À guisa de conclusão}

É preciso que saibam que eu sou assim, totus teres, atque rotundus. Que me aceitem ou me rejeitem, tanto faz. Mas só admito que me acolham por inteiro. Aprecio meus inimigos, porque costumam demarcar com clareza a coerência de meus pensamentos.

Já meus meio-amigos são insuportáveis, porque querem desculpar, como se fosse um acidente, aquilo que fundamenta minha natureza e minha essência.

Tratam disso como se fossem escorregões. "Esperem parecem dizer - e se ele se emendar?" ${ }^{4}$

\footnotetext{
${ }^{14}$ Citação extraída doJournal do ano de 1868 e que serve de epígrafe à biografia de Michelet escrita por Paule Petitier.
} 
Independentemente dos argumentos que alimentam a leitura literária de Michelet, há que se reconhecer que esta tende a ignorar a própria obra do autor, à medida que passa ao largo dos diversos momentos em que tratou da questão. Pois o fato é que esse historiador sempre fez mais do que apenas se aborrecer quando o chamavam poeta da história, provavelmente porque - e por diversas vezes - tentou definir o que faz a poeta e o que não pode fazer o historiador.

Sobretudo, sua recusa à inscrição literária teve o mérito de jamais se confundir com a idéia - simplista - de que a historiografia nada tivesse a ver com a literatura. Do muito que as aproxima, o essencial - pensa Michelet - aparece a partir do tema da linguagem:

É na história e na linguagem que podemos recolher o conhecimento do passado. A linguagem, não menos que a história, deve ser considerada como um vasto depósito para o qual os homens vêm trazer, século a século, o resultado de seus trabalhos, e em função do qual as raças extintas sobrevivem através das marcas indeléveis que deixaram de seu caráter. A história nos conserva a vida ativa de nossos pais; já a filiação das línguas, a seqüência de monumentos literários representa sua vida intelectual naquilo que ela teve de mais popular, no que toca de mais perto seu pertencimento à espécie humana. ${ }^{15}$

Remontando às notas de juventude e aos seus anos de formação, esse comentário contém em germe o tema mais perene da obra micheletiana: nem tanto a história da França, mas o problema da relação entre tempo e linguagem, motivo pelo qual, muito provavelmente, descobriu no filósofo napolitano setecentista Giambattista Vico e no filólogo alemão Jacob Grimm interlocutores frutuosos.

Se a leitura que Michelet faz desses autores é abertamente heterodoxa, a ponto de interditar as filiações, resta que as marcas

${ }^{15}$ MICHELET. Oeuvres complètes, t.I, p. 250. 
desses diálogos constituem um horizonte teórico perene na obra do historiador. Se não se pretende, neste momento, detalhar os elementos que extrai de um e de outro autor, que se registre a importância do objeto poético na configuração do pensamento de cada qual deles. ${ }^{16}$ E é na medida em que sua obra se constitui não exclusivamente, mas também como um comentário criativo que prolonga seus textos específicos sobre Vico e sobre Grimm, que se estrutura a hipótese de uma poética da história micheletiana, a saber, uma teoria sobre a maneira como o campo da poiesis se articula ao campo dos negócios humanos ao longo do tempo, o que inclui não apenas uma reflexão sobre o separa a poesia da história, mas também sobre o que as reúne.

Embora a exposição do conteúdo conceitual que fundamenta essa poética ultrapasse largamente o escopo deste artigo, vale registrar, ainda que de maneira bastante superficial, a maneira como comparece numa das muitas exposições de princípios através das quais gostava de esclarecer seu entendimento da história. Assim, em um texto inacabado que escrevera para servir de prefácio para a publicação completa de sua Histoire de France, faz questão de evocar a "crítica sibilina" da Ciência Nova, em cujo eixo estaria a pergunta sobre "como o homem, operário de si mesmo, fabrica para si suas legislações, seus poemas e seus deuses." ${ }^{17}$

\footnotetext{
${ }^{16}$ Para a recepção de Vico no Brasil, destaquem-se os trabalhos de Alfredo Bosi, Sônia Lacerda e Humberto Guido. No caso das relações entre Michelet e Vico, remetemos, sobretudo, aos trabalhos de Olivier Remaud e de Alain Pons. No caso de Jacob Grimm, há poucas remissões que não digam respeito exclusivamente ao campo da lingüística ou ao dos contos de fadas. Assim, para ilustrar o debate com uma bibliografia brasileira, reportar-nos-emos ao artigo de Sérgio da Mata e Giule da Mata, intitulado "Os irmãos Grimm entre romantismo, historicismo e folclorística.". No caso de sua relação com Michelet, ver: PETITIER. Les origines du droit français de Michelet.

${ }^{17}$ Trecho extraído de uma das versões de seu prefácio final para a edição definitiva de sua História da França. Ver MICHELET. L'Héroïsme de l'esprit. Oeuvres complètes, t. IV-Histoire de France, t. I, p. 33-42.
} 
Essa pergunta, funcionando como princípio teórico-crítico de sua historiografia, é a base de sustentação que permite inferir que, com Michelet, a categoria do poético tem uma relevância especial, uma vez dela se depreender uma interpretação autopoiética do humano. Essa interpretação - que tanta polêmica já causou com os especialistas em Vico - deve ser, portanto, compreendida como um fundamento teórico do próprio Michelet. ${ }^{18} \mathrm{E}$, nesse caso, a decorrência é a de que sua visão da história dialogaria com um certo entendimento dapoiesis em, pelo menos, dois planos.

De um lado, ela supõe que a aventura dos homens no tempo só pode ser compreendida como fabricação de si e do mundo comum, fabricação feita pelo homem tomado como autor de seus feitos. Essa autoria, porém, não se confunde com uma pura autonomia, visto Michelet introduzir nessa vocação poética uma dimensão que a ela resiste: o pendor do homem para fatalidade. Assentado na dinâmica entre criação e repetição, esse princípio historiográfico micheletiano visaria, num primeiro momento, garantir e fundamentar um campo de liberdade do humano que rivalizasse, de maneira explícita, com outras concepções historiográficas assentes, à época, em torno dos conceitos de processo mecânico, pura fatalidade ou progresso.

Num segundo instante, destaca-se de tal princípio o fato de assegurar, para os atos poéticos no sentido mais estrito, uma relevância da mesma ordem do domínio da política ou do da religião. Melhor dizendo, é possível dizer que a capacidade poética de um ato histórico - pouco importando se sua origem é política, religiosa ou artística - é o índice crítico principal de que se serve o autor.

Ambos os aspectos atestam a importância da reflexão teórica sobre o mundo do poético dentro da historiografia micheletiana. Se tal reflexão não se estanca nas obras acima

\footnotetext{
${ }^{18}$ Acerca do debate, assim como para aprofundar o tema das relações entre Michelet
} e Vico, ver, entre outros, os trabalhos de Olivier Remaud e de Alain Pons. 
destacadas, elas são, não obstante, testemunhos essenciais da presença de uma teoria poética própria a Michelet. Nesse sentido, sendo o princípio da história um princípio poiético, essa poiesis, compreendida tanto como dinâmica da história quanto tomada através de objetos propriamente poéticos, faz com que o domínio da criação transforme-se na mola mestra do método ou do pensamento de Michelet.

Ora, mas sustentar um método interpretativo capaz de dar conta da poiesis efetuada pelos autores de outros tempos implica, necessariamente, reconhecer a validade da questão dentro da sua própria atividade de historiador. Ou seja, significa uma atenção concentrada não apenas aos modos discursivos do passado, mas também aos do presente, do qual faz parte seu próprio discurso historiográfico. Daí ser ele avaliado, meditado, burilado como objeto de uma arte, ou de uma ars poética, cujo intento, porém, não se confunde com os efeitos que caracterizam a ficção:

O escritor, ocupado em aumentar os efeitos, em destacar as coisas, quase sempre adora surpreender, arrebatar seu leitor, fazendo-o exclamar: 'Ah!' Sua felicidade é transformar um fato natural em milagre. No sentido inverso o historiador tem por missão especial explicar o que parece milagroso, envolvê-lo com precedentes, com as circunstâncias que o produziram, devolvê-lo à natureza. ${ }^{19}$

É claro que o endosso de Michelet à separação entre história e literatura não distingue o corte epistêmico exatamente no mesmo ponto em que nos acostumamos a enxergá-lo. Mas é exatamente aí que, a meu ver, reside o valor de uma leitura que redescubra, na contraface da poesia de sua história, um historiador do poético, que não temeu o desafio de pensar a história com a literatura.

${ }^{19}$ MICHELET. Préface de 1869. Oeuvres complètes, t. IV, p. 23. 
Résumé: Cet article offre un panorama de l'œuvre de l'historien français Jules Michelet, tout comme de sa réception critique. L'objectif est celui de démontrer comment la frontière entre l'histoire et la littérature représente, à la fois et paradoxalement, et la condition de possibilité de sa renommée et le défis majeur qui entrave son actualisation.

Mots-clés: Frontière entre littérature et histoire; Jules Michelet; réception critique.

\section{Referências}

ARIÈS, P. O tempo da história. Lisboa: Relógio d'Água, 1986.

BARTHES, R. Aula. São Paulo: Cultrix, 1992.

BARTHES, R. Michelet. São Paulo: Companhia das Letras, 1991.

BARTHES, R. O rumor da língua. São Paulo: Brasiliense, 1988.

BOSI, A. O ser e o tempo da poesia. São Paulo: Cultrix, 1983.

CARRÉ, J.-M. Michelet et son temps. Paris : Librairie Académique Perrin et Compagnie, 1926.

GAUCHET, M. Philosophie des sciences historiques: le moment romantique. Paris: Éditions du Seuil, 2002.

GUIDO, H. Giambattista Vico: a filosofia e a educação da bumanidade. Petrópolis: Vozes, 2004.

HALÉVY, D. Les trois vies de Jules Michelet. Révue Hebdomadaire, Paris, 22 de setembro de 1928, p.77-104.

LACERDA, S. Metamorfoses de Homero. Brasília: Editora da Universidade de Brasília, 2003.

LEFORT, C. La cité des vivants et des morts. Paris: Belin, 2002.

MATA, S.; MATA, G. Os irmãos Grimm entre romantismo, historicismo e folclorística. Revista Fênix, Uberlândia, v. 3, n. 2, p. 2-24, 2006.

MICHELET, J. Correspondence générale, t. X, 1962-1965. Paris: Honoré Champion, 1999. 
MICHELET, J. Cours au Collège de France .Paris: Éditions Gallimard, 1995. 2 vols.

MICHELET, J. Histoire de France. Sainte-Marguerite sur Mer: Éditions des Équateurs, 2008. 17 vols.

MICHELET, J.Journal. Paris: Gallimard, 1976. 4 vols.

MICHELET, J. Oeuvres complètes. Paris: Flammarion,1985. 21 volumes. PETITIER, P. Jules Michelet: l'bomme-histoire. Paris: Grasset, 2006.

PETITIER, P. Les origines du droit français de Michelet. In: La question de l'origine chez les historiens français $d u X I X^{e}$ siècle. Tours: Université François-Rabelais, 1992. (Littérature et Nation, 9). p. 31-59.

PONS, A. De la "nature commune des nations" au Peuple romantique. Note sur Vico et Michelet. Romantisme, Paris, n. 9, p. 39-49, 1975.

REMAUD, O. Michelet: la magistrature de l'histoire. Paris: Michalon, 1998.

REMAUD, O. Les archives de l'bumanité: essai sur la philosophie de Vico. Paris: Seuil, 2004.

REY, J.-M. Michelet dans son histoire. In: CHIANTARETTO, J. F. (Dir.) Écriture de soi, écriture de l'bistoire. Paris: In Press Éditions, 1997. p. 125-130.

REY, J.-M. Michelet révisitant ses livres. Études, Paris, n. 3787, p. 811-22, juin 1993.

VIALLANEIX, P. Michelet, les travaux et les jours - 1798-1874. Paris: Gallimard, 1998.

Recebido para publicação em 18 de maio de 2011. Aprovado em 17 de junho de 2011. 